\title{
Effects of seed traits on the potential for seed dispersal by fish with contrasting modes of feeding
}

\author{
GER BOEDELTJE*, ${ }^{*}$ TOM SPANINGS*, GERT FLIK*, BART J. A. POLLUX*, FERDINAND A. SIBBING* \\ AND WILCO C. E. P. VERBERK ${ }^{\dagger}$ \\ *Department of Organismal Animal Physiology, Institute for Water and Wetland Research, Radboud University, Nijmegen, The \\ Netherlands \\ ${ }^{\dagger}$ Department of Animal Ecology, Institute for Water and Wetland Research, Radboud University, Nijmegen, The Netherlands \\ *Experimental Zoology Group, Department of Animal Sciences, Wageningen University, Wageningen, The Netherlands
}

\section{SUMMARY}

1. For aquatic and riparian plants, the important role of fish in seed dispersal is increasingly recognised. While the propensity of seeds to disperse is known to be a function of morphological, physical and chemical traits of the seed, in the case of fish-mediated seed dispersal (ichthyochory), it is largely unknown how seed traits modulate the potential for seed ingestion and their subsequent survival through the gut. Furthermore, which seed traits are important may vary among fish species.

2. To evaluate the role of both seed and fish traits in ichthyochory, we fed seeds of 19 aquatic and riparian plant species to fish with differing feeding mechanisms. Cyprinus carpio (common carp) has a pharyngeal 'mill', which it uses physically to crush hard food, while Oreochromis mossambicus (Mozambique tilapia) has only tiny oral and pharyngeal teeth and instead relies more on chemical digestion.

3. A number of seed traits, including hardness, size and shape, were important determinants of the potential of seeds for ichthyochory. Certain traits (e.g. seed dimensions) were more important during ingestion, whereas other traits were more important for seed survival and subsequent germination (e.g. seed hardness, mucilaginous coat). Compared to controls, germination of retrieved seeds in carp was lower in 10 and higher in two plant species, whereas for tilapia, it was lower in seven and higher in three species. Overlap between these plant species was low, indicating clear difference between the fish studied in their potential for seed dispersal. Carp increased in size during the experiment and concomitant decreases in seed survival and retrieval were found, suggesting that body size and the correlated bite force is an important fish trait in ichthyochory.

4. Overall, seed hardness, size and shape appear crucial for the survival of seeds passing through the guts of carp and tilapia. Beyond this general pattern, a greater complexity of trait-performance relationships appeared: different seed traits are involved during each of the stages of ichthyochory. Moreover, the importance of seed traits differed between carp and tilapia, with some traits having interactive and contrasting effects in both fish species. Aquatic plants with floating seeds adapted to hydrochorous dispersal were less likely to be dispersed by tilapia than plants with non-floating seeds, suggesting a dispersal trade-off between ichthyochory and hydrochory. Thus, depending on their seed characteristics, fish may offer an additional dispersal route to aquatic and riparian plants.

Keywords: common carp, Cyprinus carpio, endozoochory, Mozambique tilapia, Oreochromis mossambicus

Correspondence: Ger Boedeltje, Department of Animal Ecology, Institute for Water and Wetland Research, Radboud University, Toernooiveld 1, NL-6525 ED Nijmegen, The Netherlands. E-mails: g.boedeltje@science.ru.nl; g.boedeltje@planet.nl 


\section{Introduction}

Seed dispersal is of paramount importance for understanding and predicting the dynamics of plant distribution in response to large scale changes in habitat availability or climatic suitability (Nathan, 2006). In wetlands, the important role of fish in internal (endozoochorous) seed dispersal is increasingly recognised (Anderson et al., 2011; Horn et al., 2011), providing aquatic and riparian plants with an additional dispersal route next to hydrochorous dispersal (Boedeltje et al., 2003), wind dispersal (Soomers et al., 2013) or dispersal by water birds (Figuerola \& Green, 2002; Van Leeuwen et al., 2012). The potential of seeds for dispersal is governed by morphological, physical and chemical traits of the seeds. Knowing the importance of different seed traits for a given dispersal route enhances our general understanding of the evolution of dispersal mechanisms (e.g. Schaefer \& Schaefer, 2007; Nathan et al., 2008). For example, a flat shape and a good floating ability enhances hydrochorous seed dispersal (Boedeltje et al., 2003), capsaicinoids in chillies deter seed-eating rodents but not seed-dispersing birds (Tewksbury \& Nabhan, 2001), and differences in fruit size and colour are associated with differences in the fruit choice among frugivorous birds (Flörchinger et al., 2010). Therefore, seed traits could promote a number of dispersal routes, giving rise to polychory, that is the dispersal by more than one vector (Nathan, 2007). Alternatively, certain seed traits could promote one dispersal route, but at the same time constrain another, giving rise to dispersal trade-offs (Thompson et al., 2002; Bonte et al., 2012).

Although knowledge of seed dispersal by fish (ichthyochory) has increased over the past decades (Anderson, Saldaña Rojas \& Flecker, 2009; Anderson et al., 2011; Horn et al., 2011; Pollux, 2011; Sumoski \& Orth, 2012), few investigations have actually determined (some of) the seed traits that are important for fish-mediated seed dispersal (Agami \& Waisel, 1988; Pollux et al., 2006, 2007). A general understanding of the effect of seed traits would allow us to predict the potential for dispersal by fish in many other plants from their seed traits alone. An added complexity here is that traits affecting the likelihood of a seed being ingested and surviving passage through the gut, could itself vary among fish, interacting with inter- and intraspecific traits of the fish themselves (e.g. size, oral gape width, jaw morphology, presence and type of teeth, bite force, length of the digestive tract and digestive capability). Therefore, comparative feeding trials, employing both different species of fish and seeds from a range of plants, are essential.
Due to their complexity, such studies are currently lacking (Pollux, 2011) or are of insufficient breadth to allow generalisations (Agami \& Waisel, 1988; Adams et al., 2007; Galetti et al., 2008; Anderson et al., 2009).

Here, we attempt to fill this gap in knowledge and evaluate the role of both seed and fish traits in fish-mediated dispersal. We fed the seeds of 19 aquatic and riparian plant species, with a range of classical modes of dispersal, whose seeds vary widely in size, shape, mass, hardness, mucilaginous coat and appendices. In our feeding trials, we used two fish species with contrasting traits in terms of feeding and digestion (Table 1). The common carp (Cyprinus carpio) lacks a stomach and has a toothless mouth, but instead the pharyngeal (throat) jaw teeth are well developed: food is physically crushed and ground between lower molariform teeth and a cornified chewing pad, fixed in the base of its skull and serving as an anvil. Mozambique tilapia (Oreochromis mossambicus) lacks such molariform teeth and a chewing pad and has only many tiny teeth in its jaws and throat. However, tilapia has a better chemical digestion as it has a stomach (with can become very acidic) and a longer intestine than the carp (Table 1). Both fish species include aquatic and riparian plant seeds in their diet (e.g. Crivelli, 1981; Bowen, 1982; García-Berthou, 2001).

The process of ichthyochory can be divided into five stages (Sibbing, 1988; Pollux, 2011): (i) detection and uptake of seeds into the oral cavity, (ii) food processing and selection in the pharyngeal cavity and subsequent ingestion and (iii) retention for digestion, together affecting the (iv) viability and (v) germination probability after gut passage. We quantified frequency of ingestion, retrieval after egestion, survival and germination, and for each stage, we related the performance of plant seeds to their traits.

We expected a lower ingestion of large seeds and seeds with pointed appendages in both fish species. Seed hardness was hypothesised to promote retrieval and survival, especially in carp with its pharyngeal mill. Finally, compared to seeds in the control group, hard seeds were expected to germinate in greater numbers compared to the control group as their seed coat would be superficially damaged by the pharyngeal mill in carp or affected by the low $\mathrm{pH}$ in tilapia. Softer seeds were hypothesised to show a decreased germination.

\section{Methods}

Fish species

Common carp and Mozambique tilapia are commonly invasive outside their native ranges. The carp, native to 
Table 1 Traits related to food and food processing of common carp (Cyprinus carpio) and Mozambique tilapia (Oreochromis mossambicus)

\begin{tabular}{|c|c|c|c|}
\hline Species & C. carpio & O. mossambicus & References \\
\hline Family & Cyprinidae & Cichlidae & \\
\hline Order & Cypriniformes & Perciformes & \\
\hline Diet & $\begin{array}{l}\text { Benthic polyphagous: } \\
\text { (1) dipteran larvae, } \\
\text { (2) detritus, algae, molluscs, } \\
\text { micro- and macrocrustaceans, } \\
\text { (3) aquatic macrophytes }\end{array}$ & $\begin{array}{l}\text { Bentho-pelagic polyphagous: } \\
\text { (1) algae, phytoplankton, decaying plants, } \\
\text { (2) detritus, diatoms, zooplankton } \\
\text { micro-crustaceans, dipteran larvae, } \\
\text { (3) aquatic macrophytes }\end{array}$ & $2-4,6,11$ \\
\hline Transport & $\begin{array}{l}\text { By muscular peristalsis of palatal } \\
\text { organ in roof pharynx }\end{array}$ & By movement of pharyngeal jaws & 8,9 \\
\hline Teeth on oral jaws & Absent & $\begin{array}{l}\text { Many upper and lower oral jaw teeth, } \\
\text { very fine and pointed }\end{array}$ & $8-11$ \\
\hline Pharyngeal jaws & $\begin{array}{l}\text { Lower pharyngeal jaws movably } \\
\text { interconnected; upper pharyngeal } \\
\text { jaws replaced by horny chewing pad } \\
\text { fixed in the skull base }\end{array}$ & $\begin{array}{l}\text { Lower pharyngeal jaws fused, opposing } \\
\text { separately movable upper pharyngeal jaws }\end{array}$ & $8-11$ \\
\hline Stomach with acid secretion & Absent & Present & 10 \\
\hline $\begin{array}{l}\text { Pyloric caecae, fingerlike blind } \\
\text { sacs in the proximal intestine }\end{array}$ & Absent & Present & 10 \\
\hline $\begin{array}{l}\text { Intestine production of cellulase } \\
\text { or amylase }\end{array}$ & Absent & Absent & 10 \\
\hline $\begin{array}{l}\text { Cellulase production by micro } \\
\text { organisms }\end{array}$ & Present & Significant & 7,10 \\
\hline $\begin{array}{l}\text { Amylase production by micro } \\
\text { organisms }\end{array}$ & Significant & Significant & 5,7 \\
\hline $\begin{array}{l}\text { Relative gut length: ratio of } \\
\text { intestine length to fish SL }\end{array}$ & 2.64 & $\begin{array}{l}7.9 \text { (adults of mean length of } 10.8 \mathrm{~cm} \text { ); } \\
\text { between } 7 \text { and } 10\end{array}$ & $1,2,6$ \\
\hline
\end{tabular}

SL, standard length fish.

References: 1: Balon (2005); 2: Bowen (1982); 3: Crivelli (1981); 4: García-Berthou (2001); 5: Krogdahl, Hemre \& Mommsen (2005); 6: Mol \& Van der Lugt (1995); 7: Saha et al. (2006); 8: Sibbing (1988); 9: Sibbing et al. (1986); 10: Sibbing \& Witte (2005); 11: Trewevas (1983).

rivers draining into the Black, Caspian and Aral Sea, is currently widespread in Eurasia, North America, Australia and Africa (e.g. Koehn, 2004; Crook et al., 2013), while Mozambique tilapia, native to southern Africa, has invaded numerous waters in America, Australia and South-East Asia (Canonico et al., 2005). Both are omnivorous and potentially ingest seeds while feeding on aquatic or riparian plants, epiphytes or epifauna or foraging among detritus (Table 1).

Tilapia were reared in the laboratory of the Radboud University Nijmegen, common carp were obtained from a Dutch fish hatchery 'Viskweekcentrum Valkenswaard'. At the end of the experiment, the mean standard body length and mass of tilapia were $16.1 \pm 0.4 \mathrm{~cm}$ and $0.104 \pm 0.076$ (SE) $\mathrm{kg} \quad(n=20)$, respectively, and of common carp $15.8 \pm 0.4 \mathrm{~cm}$ and $0.119 \pm 0.028 \mathrm{~kg}(n=20)$, respectively. The length and mass of tilapia increased 1.1 and 1.5 times, respectively, and of carp 1.5 and 4.7 times, over the $c$. 5 -month experiment. Fish were fed commercial Trouvit pellets (Trouw Nutrition International, Putten, the Netherlands), at a daily ration of $1 \%$ of estimated body mass, at 9:00 and 17:00 hour. On a day that seeds were fed (at 10:30 hour), the provision of the first portion of the Trouvit pellets (normally at 9:00 hour) was at 12:30 hour.

From December 2012, fish were kept in tap water (maintained at $24{ }^{\circ} \mathrm{C}$ ) in $140 \mathrm{~L}$ tanks, which are part of a closed recirculating aquaculture system with a total volume of 2500 L. For each species, 10 separate tanks (replicates) were used for the experiments and each tank housed 10 individuals. To prevent transmission of potential pathogens, each species had its own aquaculture (filtering) system, resulting in two separate blocks of 10 tanks. Water quality in the system was maintained by a biofilter and the weekly replacement of $10 \%$ of the water. The recirculating water was continuously aerated. Water from each tank ran through a discharge pipe, in which a $200-\mu \mathrm{m}$ filter collected fish faeces, including egested seeds. 


\section{Plant species, seed collection and seed traits}

Nineteen aquatic and riparian plant species (Table 2) were used. All species are common in and along temperate freshwater habitats where fish be potential seed dispersers. Species were selected with a wide range of seed traits potentially important for ichthyochory (Table 2). Only plants whose seeds could potentially be ingested by the fish [diameter $<13.5 \mathrm{~mm}$ for a $150 \mathrm{~mm}$ standard length (SL) carp, $<18 \mathrm{~mm}$ for a $150 \mathrm{~mm}$ SL tilapia, Table 1] were selected. Either seeds or fruits were used in the feeding experiment, according to the manner in which they are available to fish in nature. The only exception was Carex pseudocyperus, of which two dispersal units were used: fruits and utricles. The utricle of C. pseudocyperus is a bottle-shaped envelope with a pointed, 2-mm long, deeply bifid 'neck' that surrounds a smooth fruit. This implies that 20 different 'seed' types (Table 2) were fed to the fish.

In 2012, mature fruits or seeds (the term 'seed' will be used hereafter to refer to seeds plus fruits) of the 19 species were collected in the Netherlands. Seeds were collected from a minimum of 10 individuals, growing in at least two populations. The seeds of riparian species were stored dry in the dark in an unheated room, whereas seeds of aquatic species were, after collection, stored outside under natural weather conditions in open 20-L tanks in tap water that was changed every 2 weeks. From 29 October 2012 until 14 March 2013, seeds of riparian species were stored in vials without water and seeds of aquatic species were stored in tap water in a dark room, both at $5{ }^{\circ} \mathrm{C}$. We realise that these differences in pre-experimental conditions between aquatic and riparian seeds could have affected subsequent effects of gut passage. However, upon drying, seeds of aquatic plants are known to become less viable (Muenscher, 1936), while wetting of dry seeds of some riparian plants (notably Impatiens glandulifera) can result in seeds going mouldy and rotting (pers. obs. G.B.). Thus, the pre-experimental conditions were chosen to retain seed viability. When the experiments started, all seeds had experienced a cold period of 108 days, which is considered sufficient to ensure germination in most of the species tested (Baskin \& Baskin, 1998).

Seed traits considered were as follows: length, width, height, mass, shape, surface structure, hardness, the presence of appendages and a mucilaginous surface (Table 2). Data were obtained from the $\mathrm{D}^{3}$-database (Hintze et al., 2013) and the LEDA-trait base (Kleyer et al., 2008) supplemented by additional measurements. Seed hardness expressed as cracking resistance (Appen- dix S1) was measured according to Van der Meij \& Bout (2000). Seed shape was quantified as the variance of unit seed dimensions (Thompson, Band \& Hodgson, 1993). Shape is dimensionless and can vary between 0 (perfectly spherical) and 0.2 (shaped like a thin disc or a slim needle; see also Bekker et al., 1998).

\section{Feeding trials}

From 14 March 2013 onwards, two feeding trials were performed weekly. In the first, seeds of 10 plant species were fed to both fish species. In the second, performed 2 days after the first, the seeds of the remaining 10 plant species were fed in a similar way. Thus, all 20 seed species were fed to the fish once per week over the whole (5 month) experimental period. Seeds of a given plant species were fed to fish in a different tank on consecutive feeding trials, thus making sure that seeds of the same species were not fed twice to fish in the same tank. Seeds were presented to the fish in dough pellets (carp: http://youtu.be/Ts60YiE2eVM; tilapia: http://youtu. be/9FyreeC0P1o).

To ensure similar mean seed sizes, masses and variances in all trials, 2300 seeds of each plant species were randomly distributed over 23 polyethylene pots: 10 for carp, 10 for tilapia and three control groups. Each pot contained 100 seeds. Prior to a trial, dry-stored seeds were kept in water for $24 \mathrm{~h}$. The actual number of seeds used depended on seed dimensions, resulting in the following seed numbers per trial: Potamogeton natans 50, I. glandulifera 60, Angelica sylvestris 70, Nymphoides peltata 70, Sagittaria sagittifolia 70 and other species 100. Before a trial, seeds were divided over $20-25$ dough pellets ( $\varnothing$ 5-6 mm), consisting of a mixture of corn flour and bread flour.

Within $1 \mathrm{~h}$ after feeding, seeds that were not taken into the mouth and any seeds that were expelled by 'spitting' (Sibbing, Osse \& Terlouw, 1986) were collected and counted. Fish were then left undisturbed for $26 \mathrm{~h}$, at which time faeces and egested seeds were collected. Preliminary tests (Agami \& Waisel, 1988; Pollux et al., 2006) had shown that tilapia and carp generally egested most undigested seeds within $24 \mathrm{~h}$. Using a binocular microscope, retrieved seeds were sorted out and counted, and stored in $25-\mathrm{mL}$ vials filled with tap water at $5{ }^{\circ} \mathrm{C}$ until the beginning of the germination experiment. In experimental weeks 1, 4 and 9, 50 seeds per species of the controls were also embedded in dough pellets. These pellets and embedded seeds then were treated in the same way as those which were fed to the fish, except that they were put into a tank, filled with tap water at $24{ }^{\circ} \mathrm{C}$, 
Table 2 Dispersal units, habitat and traits of the plant species used in the experiments

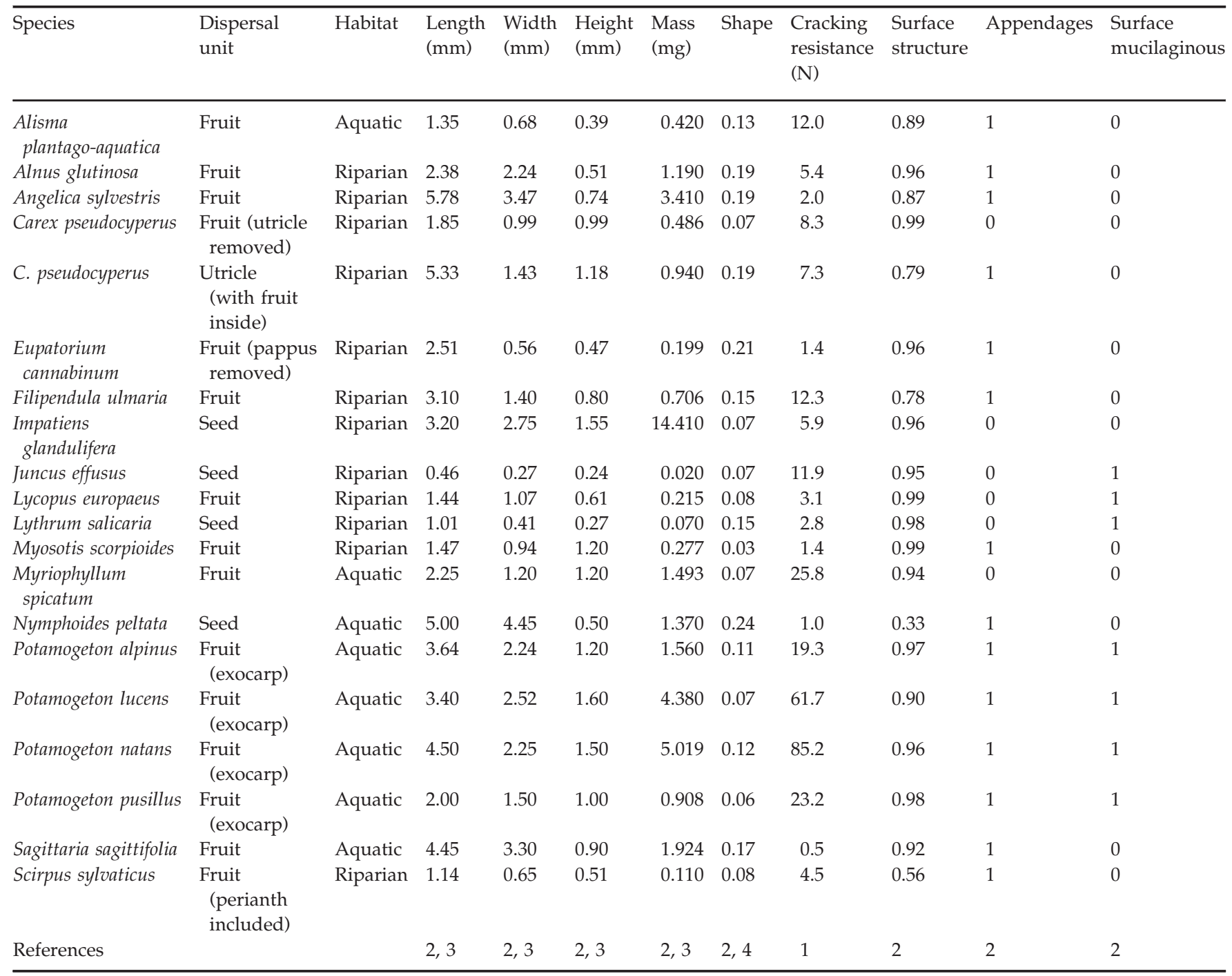

Legend appendages and surface mucilaginous: 1 = present, $0=$ absent. Terminology dispersal units follows Cappers, Bekker \& Lans (2006). References: 1: Boedeltje (details in Appendix S1); 2: Hintze et al., 2013; 3: Kleyer et al., 2008; 4: Calculation after Thompson et al. (1993).

without fish for $24 \mathrm{~h}$. After this treatment, control seeds were stored in $25-\mathrm{mL}$ vials filled with tap water at $5^{\circ} \mathrm{C}$ until the beginning of the germination experiment.

\section{The germination experiment}

On 18 June 2013, retrieved and control seeds were simultaneously set to germinate in Petri dishes $(\varnothing 9 \mathrm{~cm})$ on a double layer of Whatman No. 1 filter paper. The paper was kept water-saturated with tap water, as earlier experiments (Boedeltje, Ter Heerdt \& Bakker, 2002; Boedeltje et al., 2003) indicated that this was the optimal hydrological condition for both aquatic and riparian species. For 100 days, the dishes were placed in a climate room providing photon flux density (PAR, 400-700 nm) of $400 \mu \mathrm{mol}$ photons $\mathrm{m}^{-2} \mathrm{~s}^{-1}$ over 15 -h light at $24{ }^{\circ} \mathrm{C}$ and a night temperature of $15^{\circ} \mathrm{C}$. Fluctuating temperatures were chosen, as earlier experiments (Thompson \& Grime, 1983) had shown that at least five riparian species (Eupatorium cannabinum, Filipendula ulmaria, Juncus effusus, Lythrum salicaria and Scirpus sylvaticus) require fluctuating temperatures for good germination. Previous experiments (e.g. Boedeltje et al., 2002; Hay, Probert \& Dawson, 2008) have demonstrated that aquatic species are also able to germinate under such conditions. In the first week after incubation, each dish was inspected every second day, in the second to the fourth weeks twice per week, and in the remaining period once per week. During an inspection, seedlings were counted and removed. After the germination period had ended, 
non-germinated seeds were checked for viability. Seeds that collapsed when pinched were considered dead. Remaining firm seeds were cut so that the embryo was bisected after which they were placed in a $1 \%$ solution of 2,3,5-triphenyl-2H-tetrazolium chloride (TTC) in watch glasses for $24 \mathrm{~h}$ at $25{ }^{\circ} \mathrm{C}$ to determine the presence of living tissue, an indication of seed viability (Cottrell, 1947). Embryos that turned red or pink were considered to be viable.

\section{Data analyses}

We used generalised linear mixed models (GLMMs) to test for differences between fish species, plant species and interaction effects regarding the number of ingested, retrieved, viable and germinated seeds. Data were fitted to GLMMs with a binomial error distribution and a log link function. Instead of pre-selecting a given covariance type, we fitted the available covariance types and selected the one that minimised the residuals' dispersion and provided the best fit (based on the lowest AIC score; cf. Latorre, Larrinaga \& Santamaria, 2013). All models included fish species, plant species and their interaction as fixed factors and plant block (each of the 20 seed species were fed 10 times, constituting 10 'plant blocks') as random factor.

For each fish species, the effects of seed traits and the interaction of some traits on the total number of ingested, retrieved, viable and germinated seeds were tested using GLMMs with a binomial error distribution and a $\log$ link function. Seed dimensions, mass and hardness were log-transformed to improve normality and attain a more even distribution of trait values. Seed traits were only included in the initial model when they explained more than 5\% of the deviation on their own. We also included a selection of interactions between mass, shape, hardness and the presence of a mucilaginous layer: mucilaginous*shape, mucilaginous*hardness, mass*hardness and mass*shape. To prevent overfitting of the data, we simplified the initial model by excluding traits that were correlated (giving preference to seed mass over seed height, seed length or seed width) or traits that did not have a large contribution to the model fit. The threshold employed was that explained deviation of the simplified model should not be reduced more than $2 \%$ compared to the initial model. To facilitate comparisons of effect sizes, all variables were standardised (rescaled to have a mean of zero and a standard deviation of 1). Analyses were performed using the package lme4 (Bates \& Sarkar, 2007) in R (R-Development-CoreTeam, 2013).
As multispecies analyses concerned with functional relationships should control for species interdependence (D’hondt \& Hoffmann, 2011), we additionally performed analyses that took phylogenetic relationships into account (Appendix S2). We calculated phylogenetically independent contrasts using the package APE in R (Paradis, Claude \& Strimmer, 2004), making use of a published tree of plants that included our 19 plant species (Durka \& Michalski, 2012).The outcome of the models taking phylogeny into account (Appendix S2) did not lead to a different interpretation of our results, so for the sake of clarity, we only present the binomial model results.

To investigate whether the observed distributions of germinated and non-germinated and of viable and nonviable seeds retrieved from the faeces of each fish species differed from those of control seeds, we used $\chi^{2}$ tests. To test whether germination and viability differed between fish species for a given seed species, MannWhitney $U$-tests were used.

\section{Results}

Ingestion

Seed ingestion varied significantly between fish species $\left(F_{1,360}=6.89, \quad P<0.01\right)$ and plants $\left(F_{19,360}=4.34\right.$, $P<0.001)$; in addition, there was a significant plant*fish effect $\left(F_{19,360}=2.11, P<0.01\right)$. For carp, the mean seed ingestion of plant species ranged between $88.9 \%$ for Lycopus europaeus and $100 \%$ for Myriophyllum spicatum (Fig. 1). For tilapia, ingestion was lower, ranging between $28.4 \%$ for I. glandulifera and $97.5 \%$ for J. effusus (Fig. 1).

Seed ingestion was strongly affected by seed mass and therefore also by seed dimensions, because these traits are highly correlated (results not shown), with light small seeds being ingested in greater numbers than heavy, large seeds (Figs 3 \& 4). For carp, large seeds were ingested less when they were flat and elongated (Fig. 3).

\section{Seed retrieval}

Seed retrieval varied significantly between fish $\left(F_{1,359}=114.85, P<0.0001\right)$ and plant species $\left(F_{19,359}=\right.$ 24.77, $P<0.0001)$; in addition, there was a significant fish*plant effect $\left(F_{19,359}=4,69, P<0.001\right)$. In 16 plant species, seed retrieval was significantly lower in carp than in tilapia (Fig. 1). With the exception of M. spicatum and the four Potamogeton species, seed retrieval was extremely 
Fig. 1 The proportion of the total number of seeds fed that were ingested, retrieved in faeces, viable and germinated after gut passage, for each plant species.

Fig. 2 Seed retrieval of the five species with the hardest seeds in faeces of carp during the research weeks. Time effects in seed retrieval were investigated using GLMM: Potamogeton lucens $\left(F_{1,8}=0.29\right.$; $P=0.603)$, Potamogeton natans $\left(F_{1,8}=6.04 ; P=0.040 *\right)$, Potamogeton alpinus $\left(F_{1,8}=2.82 ; P=0.131\right)$, Myriophyllum spicatum $\left(F_{1,8}=11.30 ; P=0.010 *\right)$ and Potamogeton pusillus $\left(F_{1,8}=15.48\right.$;

$\left.P=0.004^{*}\right)$. Seed hardness of the species are as follows: $M$. spicatum $=26 \mathrm{~N}$; $P$. alpinus $=19 \mathrm{~N} ; P$. lucens $=62 \mathrm{~N}$; $P$. natans $=85 \mathrm{~N}$ and $P$. pusillus $=23 \mathrm{~N}$.
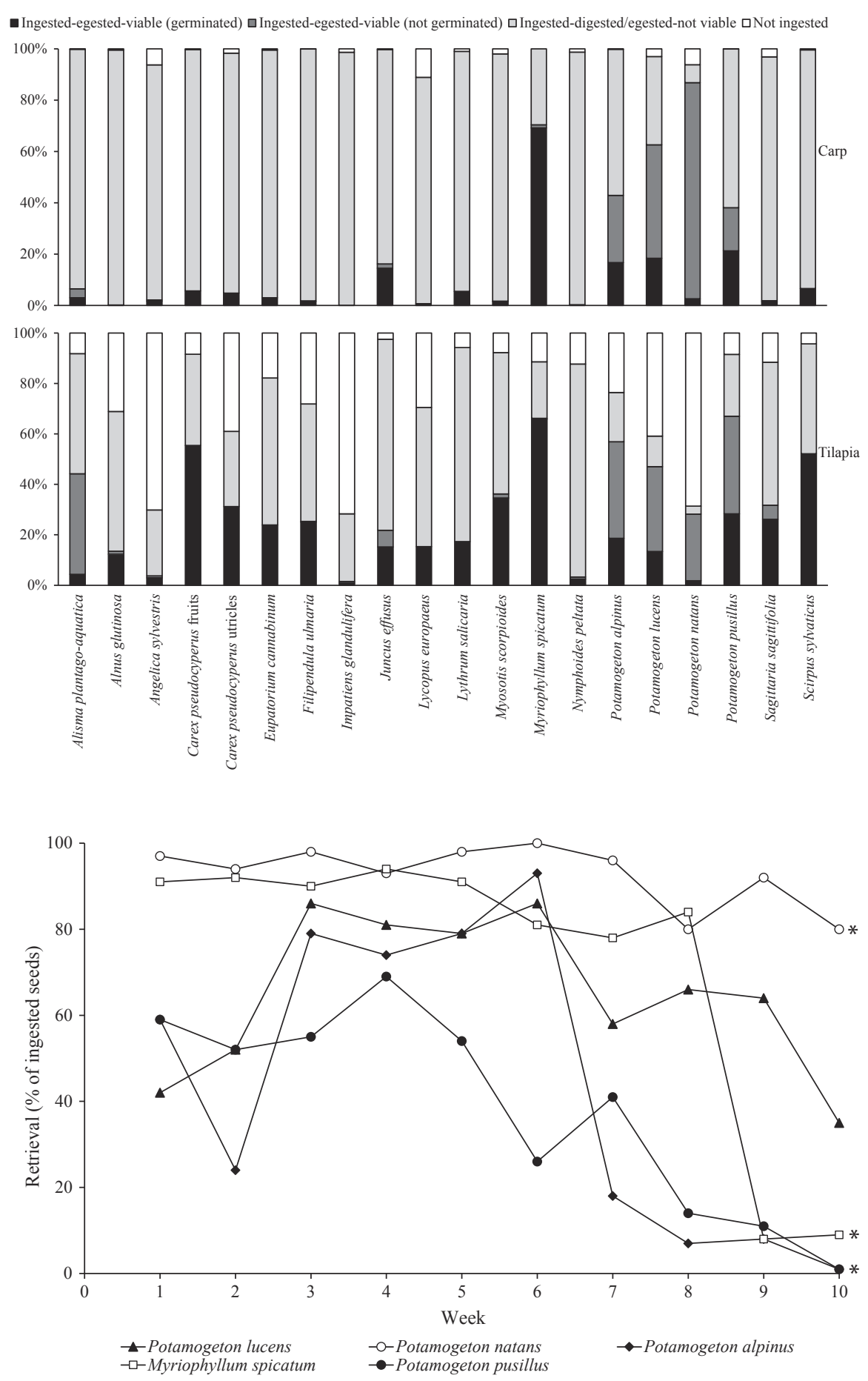

low for carp (Fig. 1) as most seeds were crushed and only seed fragments were found. Consequently, retrieval of seeds in carp was largely explained by their hardness (Figs 3 \& 4). Even for the hardest seeds, retrieval declined in later trials (Fig. 2). For tilapia, mean retrieval percentage was lowest in I. glandulifera (19.4\%) and highest in P. natans (89.1\%) (Fig. 1). No seed fragments were observed in tilapia faeces. Both seed hardness and mass governed retrieval in tilapia with hard, heavy seeds being retrieved more frequently than soft, light seeds (Figs 3 \& $4)$.

\section{Viability of seeds}

Viability of retrieved seeds varied significantly between plant species $\left(F_{19,359}=27.317, P<0.0001\right)$. There was 
CARP
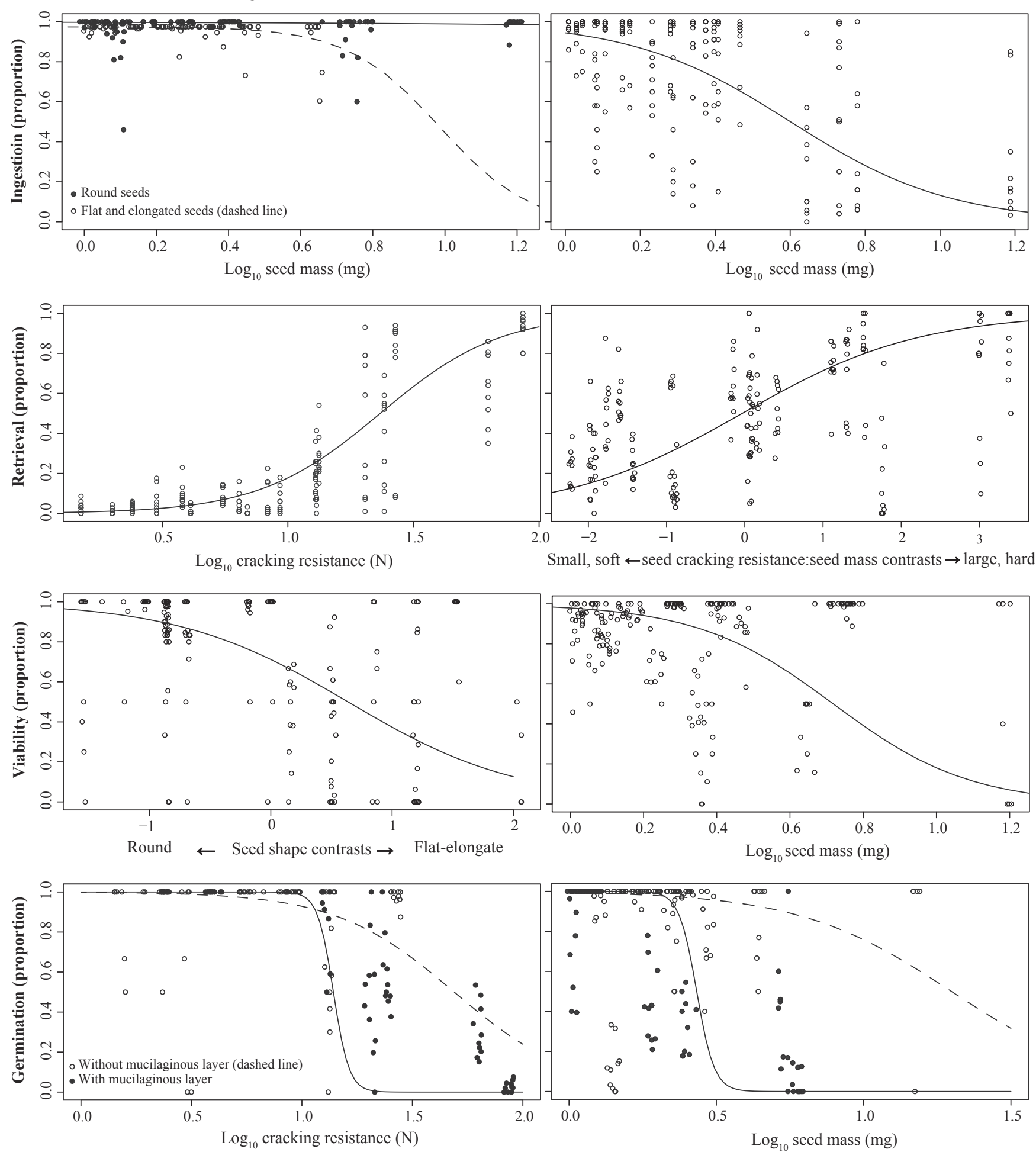

Fig. 3 Relationship between ingestion, retrieval, viability and germination and some seed traits for each fish species. Left hand panels relate to carp, while right hand panels relate to tilapia.

also a significant fish*plant effect $\left(F_{19,359}=5.157\right.$, $P<0.0001$ ). With respect to viability of the control seeds (Appendix S3), I. glandulifera had only $18 \%$ viability and appeared to be an outlier. Viability of the other species ranged from $40 \%$ (Alnus glutinosa) to $100 \%$ (P. natans, Potamogeton pusillus). The total number of viable egested 
seeds varied significantly between fish and plant species (Fig. 1; Appendix S4). Compared to the control seeds, the viability of these seeds was lower in 12 and similar in eight species in carp. Species with lower viability were, among others, Alisma plantago-aquatica, A. glutinosa and F. ulmaria. In tilapia, viability was significantly lower in only six species (e.g. A. sylvestris and N. peltata).

The viability of egested seeds was governed by quite different traits for both fish species. In carp, it was greater in round seeds (Fig. 3) and when seeds were both hard and heavy (Fig. 4). In tilapia, shape did not affect survival strongly, but seed hardness promoted it, but only in light seeds. In both fish species, seed viability was higher in hard seeds with a mucilaginous layer (Fig. 4).

\section{Germination of seeds}

Germination of retrieved seeds varied significantly between plant species $\left(F_{19,321}=37.210, P<0.0001\right.$. There was a significant fish*plant effect $\left(F_{19,321}=6.219\right.$, $P<0.0001)$. Germination percentage of the control seeds
(Appendix S3) ranged from $4.0 \%$ (I. glandulifera) to 98.7\% (L. salicaria). Compared to control seeds, germination of retrieved seeds was significantly lower in 10 and higher in two plant species in carp (Appendix S5). In tilapia, such germination was lower for seven and higher for three species (Appendix S5). The germination speed, expressed as $\mathrm{G}_{50}$ (the number of days after which $50 \%$ of the seeds had geminated), varied between species (Appendix S6). Compared to the control seeds, the $\mathrm{G}_{50}$ of retrieved seeds showed that germination was faster in two species (Potamogeton lucens and utricles of C. pseudocyperus) for both fish species (lower $G_{50}$ ). In addition, the $G_{50}$ of seeds retrieved from tilapia was lower for P. pusillus and S. sagittifolia, but higher for A. glutinosa than in control seeds.

The interaction between seed hardness and mass was the best predictor for germination of retrieved seeds in both fish species (Fig. 4), whereby hard, heavy seeds had the lowest germination, corresponding to the relatively low germination percentages of the Potamogeton species (Figs $1 \& 3$ ). The interaction between hardness and the presence of a mucilaginous layer was the second most important predictor in both fish. Hard seeds with a

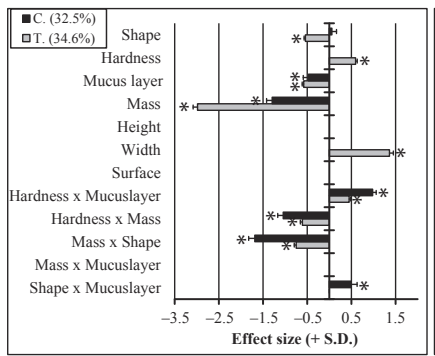

Ingestion

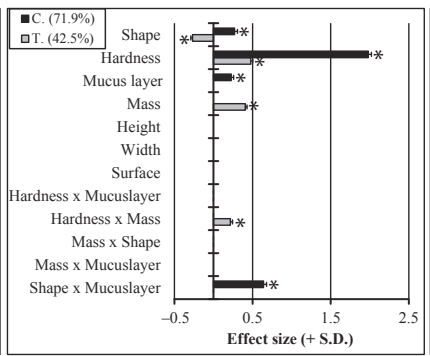

Retrieval

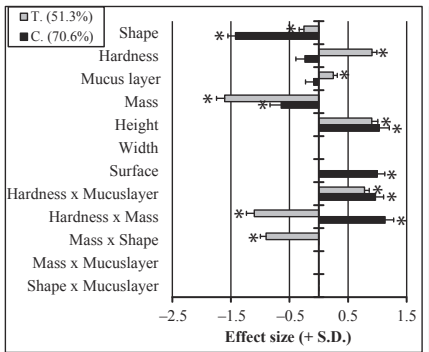

Viability

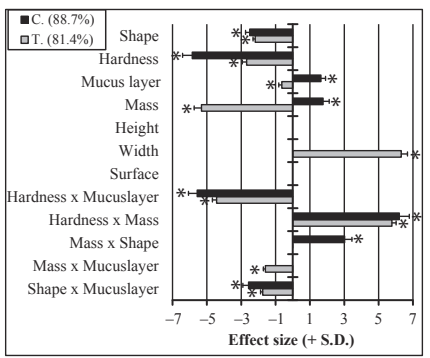

Germination

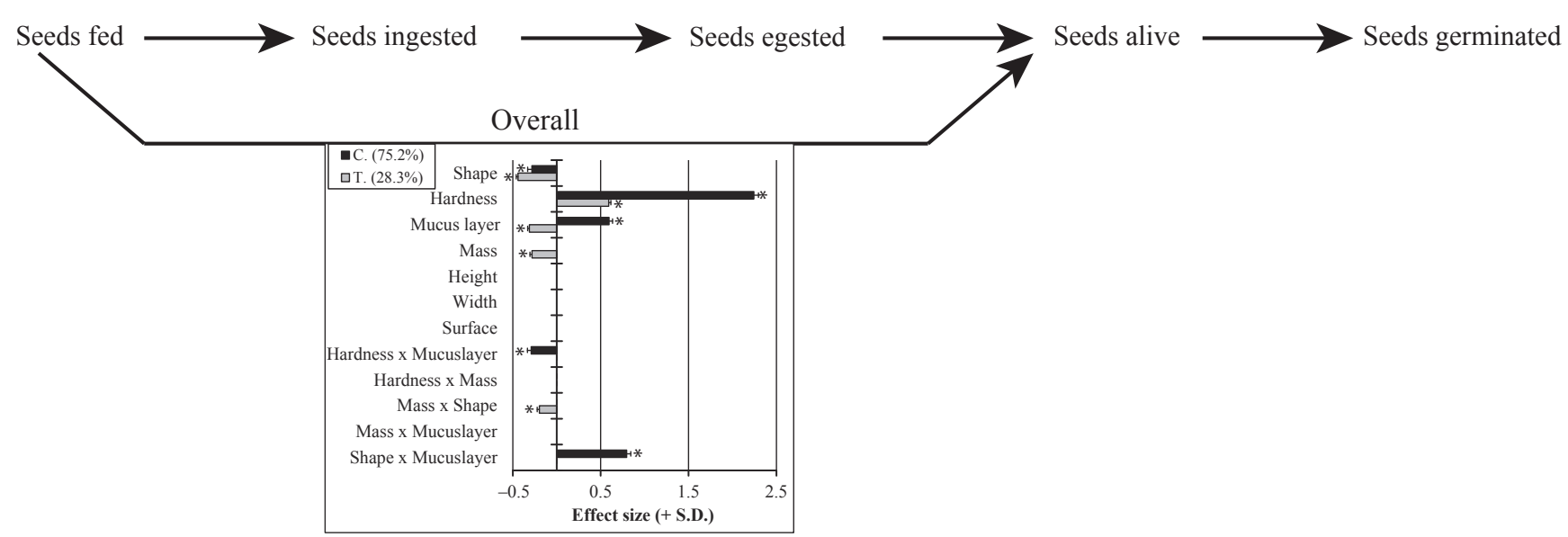

Fig. 4 Overview of the importance of the various seed traits during the different stages of seed dispersal (ingestion, retrieval, germination and viability as well as the overall effect from ingestion to viability) as indicated by their effect size (+SD). Positive effect sizes indicate positive relationships, while negative effect sizes indicate negative relationships. For each dispersal stage, the effect sizes for each trait are shown separately for carp (C.) and tilapia (T.), together with the explained deviation (\%) and their significance $(* P<0.05)$. 
mucilaginous layer had lower germination than similar seeds without this layer (Fig. 4).

\section{Overall effects of seed traits on the survival of seeds fed}

For carp, seed hardness was the most important trait for seeds to survive the different stages of ichthyochorous dispersal: ingestion, passage through the pharyngeal mill and then the rest of the gut to egestion (Fig. 4). The presence of a mucilaginous layer additionally contributed to survival, although to a lesser extent (Fig. 4). Although much less deviance could be explained in the models for tilapia, hardness was also important for survival. An elongated shape, a small mass and the absence of a mucilaginous layer were further crucial traits for seeds to survive gut passage in tilapia (Fig. 4).

\section{Discussion}

\section{Seed dispersal stages}

With respect to fish-mediated seed dispersal, this study focussed on (i) seed ingestion, (ii) seed retrieval and (iii) seed viability after gut passage (expressed in germination plus prolonged dormancy) (Pollux et al., 2006; Pollux, 2011). Common carp protrudes its jaws for fast and directed suction, even deep into the sediment, and is also able to select and handle small particles such as seeds (Sibbing et al., 1986). We found, however, overall high seed ingestion by carp, that was fairly indiscriminate. The only indication of a minor seed size effect was that the $2 \%$ of seeds that were not ingested were more often heavy, flat and elongated. Seed ingestion by tilapia partly supported our hypothesis that large seeds were ingested less. It is unlikely that gape size limits food intake in tilapia, because it was wider than the diameter of the pellets fed (Table 1) and it is even wider than in carp. No effect of pointed seed appendages was found, but seeds with a mucilaginous layer were ingested less. The lower suction speed and the tiny unicuspid teeth may limit the efficiency of tilapia in handling relatively heavy, large and mucilaginous seeds.

Seed hardness promoted retrieval and survival. The beneficial effect of seed hardness has also been demonstrated for endozoochorous dispersal in cattle (Gardener, McIvor \& Jansen, 1993; Ramos, Robles \& Castro, 2006) and waterbirds (de Vlaming \& Proctor, 1968). The importance of seed hardness for surviving the bite force of carp is further suggested by the decline over time in the number of retrieved seeds and the associated increase in the number of seed fragments of M. spicatum,
P. pusillus and Potamogeton alpinus (Fig. 2). Although learning behaviour or 'gut adjustment' to the experimental diet also may play a role, this is likely to be associated with an increase in bite force of the carps over the total research period (150 days). The mass of carp increased more than fourfold, which is likely to have resulted in a more than doubling of bite force [under the assumption that mass increases cubically with length and the cross section of a (bite) muscle increases quadratically, a fourfold increase in mass gives a 2.5 -fold increase in bite force $\left.\left(4^{2 / 3}\right)\right]$. As no fragments of the five hardest seeds were found initially, we can infer the bite force of carp at the start of the experiment to be $<19 \mathrm{~N}$ (=cracking resistance of $P$. alpinus). However, in the last 2-3 weeks, almost all seeds of M. spicatum, P. pusillus and $P$.alpinus were cracked, indicating that the bite force of carp had increased beyond $26 \mathrm{~N}$ (cracking resistance of M. spicatum), but was still $<62 \mathrm{~N}$ (=cracking resistance of $P$. lucens). It has previously been reported (Agami \& Waisel, 1988) that carp (of unknown size) may crush seeds of Najas marina. Although less pronounced than in carp, retrieval of hard seeds was also higher in tilapia. Similarly, Agami \& Waisel (1988) retrieved four times more hard than soft seeds of $N$. marina after gut passage through an unspecified species of tilapia. In addition, retrieval of hard seeds was further promoted by seed mass in tilapia, but not in carp. The opposite is reported for waterbirds by Van Leeuwen et al. (2012) who found a negative correlation between seed mass and seed retrieval. This indicates that a given seed trait, such as seed mass, may have opposite effects on seed dispersal across different vectors. Similarly, we found contrasting effects across both fish species for the effect of a mucilaginous layer. In carp, but not tilapia, there was an additional but modest effect of a mucilaginous layer, providing support for the assertion that a mucilaginous seed coat acts as a lubricant during gut passage (Lobova et al., 2003). In tilapia, ingestion of seeds was negatively affected by a mucilaginous layer, while survival of retrieved seeds was positively related to a mucilaginous layer. The negative effect of a mucilaginous layer on seed ingestion at least partly explains its overall negative effect in tilapia (Fig. 4).

Previous studies report mixed responses in seed germination in plant species after ingestion by different frugivores (Rodríguez-Pérez, Riera \& Traveset, 2005; Traveset, Robertson \& Rodríguez-Pérez, 2007; Brochet et al., 2010). After ingestion by fish, improved germination has been reported for $N$. marina and Ruppia maritima in tilapia (Agami \& Waisel, 1988) and for Morus rubra 
and Forestiera acuminata in channel catfish (Ictalurus punctatus) (Chick, Cosgriff \& Gittinger, 2003), whereas unaltered germination was observed for Sparganium emersum and decreased germination for S. sagittifolia in carp (Pollux et al., 2006). The faster germination observed here (compared to the control seeds) of a few plant species that passed the gut of carp and tilapia can be both advantageous and disadvantageous. Early germinating seeds may have a competitive advantage, but seedlings may also die of desiccation, pathogens or herbivores (Figuerola \& Green, 2004; Traveset et al., 2007).

In carp, we demonstrated an improvement in the germination for two hard-seeded species, and in tilapia for three different hard-seeded species and a reduction for seven soft-seeded species. This suggests that mixed responses after passing through the fish gut can be at least partly linked to seed hardness. The hard-seeded Potamogeton species in our experiments generally exhibited low germination percentages (Fig. 1) and slow germination (Appendix S6). Potamogeton species are known for their relatively slow germination and low germination percentages in experimental studies (Boedeltje et al., 2002; Hay et al., 2008). Such slow germination has been suggested to constitute a cost of seed hardness (Traveset et al., 2007). Our result highlights the potential benefit of seed hardness of enhanced dispersal by fish.

Our hypothesis that seed viability of retrieved seeds would be higher in hard-seeded than soft-seeded species was generally supported by the results for both fish species. Still hardness did not uniformly enhance viability across all seeds but acted in a context-dependent manner (see Verberk, van Noordwijk \& Hildrew, 2013). In carp, viability of hard seeds was more pronounced when these were also large and had a mucilaginous layer. In tilapia, hard seeds with a mucilaginous layer similarly showed a better viability, but in tilapia, viability was also enhanced for small seeds, contrasting with the higher viability of large seeds in carp.

For eight aquatic and riparian species, Brochet et al. (2010) showed that passage through the gut of common teal (Anas crecca) increased the proportion of viable seeds, suggesting selective digestion of non-viable seeds. A mucilaginous layer seems to enhance survival of retrieved seeds uniformly, possibly by offering protection against intestinal fluids (Yang et al., 2012 and references therein).

\section{Overall survival of gut passage}

Janzen (1984) hypothesised that seeds adapted to endozoochory by mammals are small, round and hard. Our analyses of the viability of seeds that were fed to common carp and Mozambique tilapia show that hardness is also of paramount importance for seeds to survive gut passage in fish. Further, spherical seeds were found to survive gut passage in fish better than elongate or flat seeds, which could be related to the favourable surfacemass ratio. However, our analysis of the different stages also shows that underneath this general pattern of greater survival in hard and round seeds lies a greater complexity of trait-performance relationships. Different seed traits are involved during each of these stages (ingestion, retrieval, viability/germination) (Figs 3 \& 4) and traits may have opposite effects across these stages. For example, in tilapia, retrieval was enhanced in larger seeds, but survival was enhanced in smaller seeds (Fig. 3). Moreover, the effect of traits also depends on other seed characteristics, as illustrated by significant interactions terms between traits (Fig. 4). Finally, the importance, identity and even the mode of action of seed traits (positive or negative) varies between our two fish species (Fig. 4). This illustrates that the adaptive value of traits is context dependent (see Verberk et al., 2013) and that the successful dispersal of seeds is controlled by many interacting traits, the effects of which we have started to unravel in this study.

\section{Common carp and Mozambique tilapia as potential seed dispersers}

Theproportion of fed seeds that areviable(Fig. 5) can beused to predict the probability of dispersal, as it integrates the probability of ingestion, retrieval and survival. Only $M$. spicatum and the Potamogeton species have a substantial (>20\%) probability of being dispersed by carp. However, this seems toapply only to smallercarp with a relativelylow biting force. Only plants with very hard seeds are likely to be dispersed by larger carp. Our results that smaller carp may be better disperser contrasts with the study of Galetti et al. (2008) in the pacu fish (Piaractus mesopotamicus). They found that the largest individuals were the best dispersers of fruits of the palm Bactris glaucescens. Further studies are needed to determine in more detail the effect of body size (biting force) on the potential of seed dispersalbycarpand otherfish.

In tilapia, 14 plant species have a probability of $>20 \%$ of being dispersed, including seven species with a probability of $>40 \%$ (Fig. 5). Here, M. spicatum, the Potamogeton species, S. sylvaticus and C. pseudocyperus have the highest dispersal probability.

Whether seed ingestion is likely in nature, and whether plants have evolved in relation to this extra dispersal route remain open questions. All the plant species 


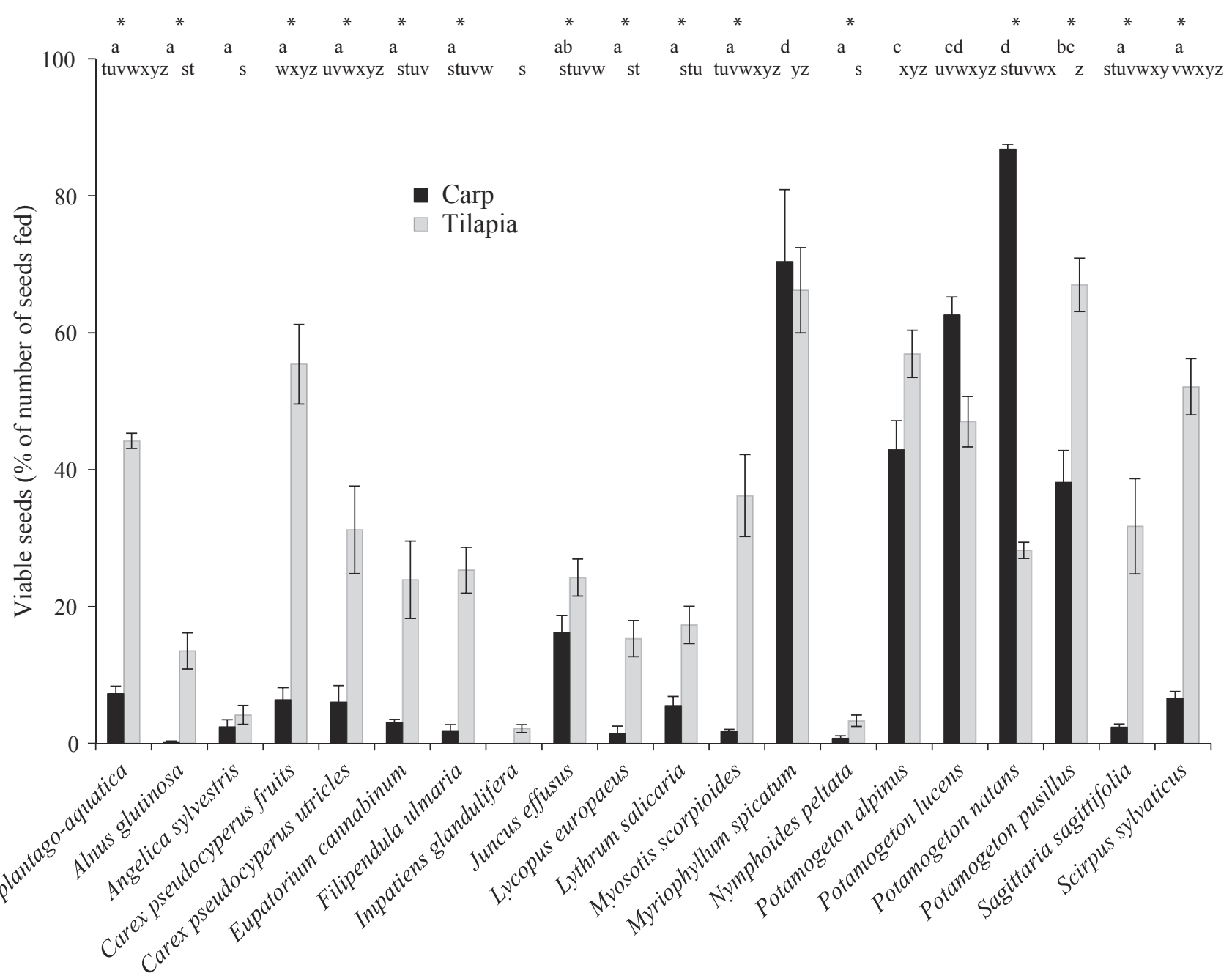

Fig. 5 Mean percentages of viable seeds $( \pm \mathrm{SE})$ of the number of seeds fed to carp and tilapia. Viability refers to the number of seeds that germinated + the number of seeds that showed a positive tetrazolium test. Carp: $N=10$, except for Alisma plantago-aquatica (9), Angelica sylvestris (8), Carex pseudocyperus fruits (9), C. pseudocyperus utricles (8), Eupatorium cannabinum (9), Impatiens glandulifera (1), Lycopus europaeus (4), Nymphoides peltata (4) and Sagittaria sagittifolia (8). Tilapia: $N=10$, except for A. sylvestris (9), I. glandulifera (7) and Juncus effusus (9). *Significant $(P<0.05)$ difference between carp and tilapia; without asterisk: not significant. Different letters indicate significant differences $(P<0.05)$ between species: a- $\mathrm{d}$ for carp; $\mathrm{s}-\mathrm{z}$ for tilapia.

used in the experiment overlap with the current range of common carp (http://www.discoverlife.org). Fewer plant species (e.g. M. spicatum, P. natans and P. pusillus) (partly) overlap with the current range of Mozambique tilapia, but related plant species with similar seed traits do co-occur with tilapia. Both fish species are omnivorous and opportunistic feeders, inhabiting a wide range of potentially vegetated waterbodies (Bowen, 1982, Canonico et al., 2005; Doupé \& Burrow, 2008). Thus, they may ingest plant seeds when foraging among detritus or on aquatic plants.

Compared to seeds of riparian species, seeds of aquatic species, especially non-floating seeds, are more likely to be ingested. Under the assumption that ichthyochory offers a significant fitness advantage to the seeds, one would expect those seeds to be better adapted to gut passage. Indeed, aquatic plants showed higher viability after gut passage for both fish species and, for tilapia, non-floating seeds of aquatic plants show the highest performance (Fig. 6). These results suggest a dispersal trade-off between hydrochory and ichthyochory, with non-floating seeds being at a disadvantage when it comes to hydrochorous dispersal, but being more likely to be dispersed by fish. Our results may indicate that the dispersal pathway offered by fish is evolutionarily important for aquatic and riparian plants. Together with dispersal via waterbirds (Soons et al., 2008; Van Leeuwen et al., 2012), wind (Soomers et al., 2013) and water 


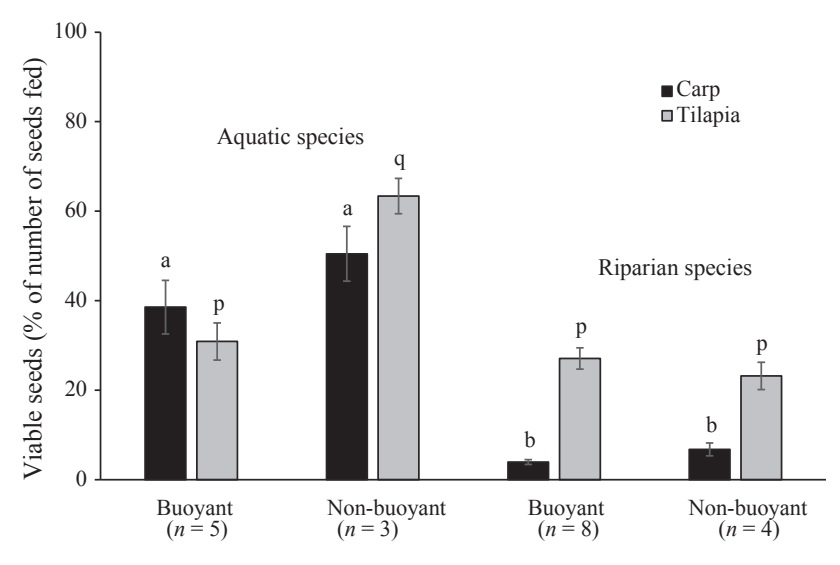

Fig. 6 Proportion of dispersible seeds (expressed as the proportion of seeds fed that were egested and viable) for the plant species used, classified by habitat and floating ability, a proxy for hydrochorous dispersal. Buoyant: mean floating period $>100$ days; nonbuoyant: mean floating period $<0.2$ day. For each fish species, different letters indicate significant differences $(P<0.05)$ (ANOVA followed by a Tukey's range test; Carp: $F=38.49, P<0.001$, Tilapia: $F=21.19, P<0.001)$.

(Boedeltje et al., 2003), fish may thus enhance gene flow between populations for species that rely predominantly on hydrochorous dispersal of vegetative diaspores (Boedeltje et al., 2003; Riis \& Sand-Jensen, 2006). Moreover, vectors may interact, for example when fish-eating birds consume fish with seeds inside them, aquatic plant seeds may even travel between hydrological catchments (cf. Green et al., 2008).

The distance which seeds are dispersed depends on the seed retention time and fish body size, spatial migratory patterns and swimming speed. Using tagged individuals, it was demonstrated (Jones \& Stuart, 2009) that movement patterns of common carp are complex: some moved large distances $(>127 \mathrm{~km})$, while others remained within $5 \mathrm{~km}$ of the tagging site. The ability for rapid movement (up to $0.9 \mathrm{~km} \mathrm{~h}^{-1}$ ) allows carp to spread quickly (Jones \& Stuart, 2009). In tilapia, both upstream and downstream dispersal has been documented, with the spread being more rapid in an upstream direction (Hutchison, Sarac \& Norris, 2011). In an Australian river, tilapia were found at sites spread over more than $500 \mathrm{~km}$ of waterway within 2 years of their initial discovery. This implies that if specific seeds are ingested by either carp or tilapia, they may be potentially dispersed over several kilometres, given a retention time of $8 \mathrm{~h}$ or more in carp (Pollux et al., 2006) and tilapia (Agami \& Waisel, 1988).

In conclusion, there exist large interspecific differences in seed dispersal efficiency that can be attributed to the traits of both fish and plant seeds. Crucial is the bite force that common carp may exert on seeds when passing the pharyngeal mill. From the perspective of the seed, hardness is the major life-history trait to withstand this force. Seeds of only five plant species were sufficiently resistant to survive gut passage in carp in large numbers. Moreover, bite force increased with age in carp, greatly reducing seed survival after gut passage. Therefore, carp smaller than $15 \mathrm{~cm}$ are likely to perform the majority of internal seed dispersal of aquatic and riparian plants. Overall, round, hard seeds survived gut passage best. However, different seed traits are important during ingestion, retrieval and germination. Traitperformance relationships were context dependent and differed between the two fish studied. Nevertheless, both fish species may provide plants with an additional route of dispersal, with ichthyochorous dispersal particularly important for aquatic plants with non-floating seeds.

\section{Acknowledgments}

We thank Jikkie Boedeltje-Elzinga for her help in hiding seeds in dough pellets and counting seeds for the germination experiments, Marij Orbons for her help in counting seedlings during the germination experiments and Eelke Jongejans for statistical advice. With the help of Oliver Tackenberg (Goethe University, Frankfurt), measurements were made on seed traits of five species. We thank Peter Snelderwaard (Leiden University) for giving the opportunity and help to GB to measure the cracking resistance of experimental seeds. Furthermore, thanks to Joost Caumanns and Joost van Erp, who laid the foundation of this research in their A-level master thesis. Finally, we highly appreciate the constructive criticism of Andy J. Green, Alan Hildrew and an anonymous referee that improved the manuscript.

\section{References}

Adams S.B., Hamel P.B., Connor K., Burke B., Gardiner E.S. \& Wise D. (2007) Potential roles of fish, birds, and water in Swamp Privet (Forestiera acuminata). Southeastern Naturalist, 6, 669-682.

Agami M. \& Waisel Y. (1988) The role of fish in the distribution and germination of seeds of the submerged macrophytes Najas marina L. and Ruppia maritima L. Oecologia, 76, 83-88.

Anderson J.T., Nuttle T., Saldaña Rojas J.S., Pendergast T.H. \& Flecker A.S. (2011) Extremely long-distance seed dispersal by an overfished Amazonian frugivore. Proceedings of the Royal Society B-Biological Sciences, 278, 3329-3335. 
14 G. Boedeltje et al.

Anderson J.T., Saldaña Rojas J.S. \& Flecker A.S. (2009) High-quality seed dispersal by fruit-eating fishes in Amazonian floodplain habitats. Oecologia, 161, 279-290.

Balon E.K. (2005) About the oldest domesticates among fishes. Journal of Fish Biology, 65(Suppl. A), 1-27.

Baskin C.C. \& Baskin J.M. (1998) Seeds, Ecology, Biogeography, and Evolution of Dormancy and Germination. Academic Press, New York, NY.

Bates D.M. \& Sarkar D. (2007) lme4: Linear Mixed-Effects Models Using S4 Classes. R package version 0.99875-6.

Bekker R.M., Bakker J.P., Grandin U., Kalamees R., Milberg P., Poschlod P. et al. (1998) Seed size, shape and vertical distribution in the soil: indicators of seed longevity. Functional Ecology, 12, 834-842.

Boedeltje G., Bakker J.P., Bekker R.M., Van Groenendael J.M. \& Soesbergen M. (2003) Plant dispersal in a lowland stream in relation to occurrence and three specific life-history traits of the species in the species pool. Journal of Ecology, 91, 855-866.

Boedeltje G., Ter Heerdt G.N.J. \& Bakker J.P. (2002) Applying the seedling-emergence method under waterlogged conditions to detect the seed bank of aquatic plants in submerged sediments. Aquatic Botany, 72, 121-128.

Bonte D., Van Dyck H., Bullock J.M., Coulon A., Delgado M., Gibbs M. et al. (2012) Costs of dispersal. Biological Reviews, 87, 290-312.

Bowen S.H. (1982) Feeding, digestion and growth - qualitative considerations. In: The Biology and Culture of Tilapias (Eds R.S.V. Pullin \& R.H. Lowe-McConnell), pp. 141-156. ICLARM conference Proceedings 7. International Center for Living Aquatic Resources Management, Manila, Philippines.

Brochet A.-L., Guilleman M., Gauthier-Clerc M., Fritz H. \& Green A.J. (2010) Endozoochory of Mediterranean aquatic plant seeds by teal after a period of desiccation: determinants of seed survival and influence of retention time on germinability and viability. Aquatic Botany, 93, 99-106.

Canonico G.C., Arthington A., McCrary J.K. \& Thieme M.L. (2005) The effects of introduced tilapias on native biodiversity. Aquatic Conservation: Marine and Freshwater Ecosystems, 15, 463-483.

Cappers R.T.J., Bekker R.M. \& Lans J.E.A. (2006) Digitale Zadenatlas van Nederland. Digital Seed Atlas of the Netherlands. Barkhuis Publishing and Groningen University Library, Groningen.

Chick J.H., Cosgriff R.J. \& Gittinger L.S. (2003) Fish as potential dispersal agents for floodplain plants: first evidence in North America. Canadian Journal of Fisheries and Aquatic Sciences, 60, 1437-1439.

Cottrell H.J. (1947) Tetrazolium salt as a seed germination indicator. Nature, 159, 748.

Crivelli A.J. (1981) The biology of the common carp, Cyprinus carpio L. in the Camargue, southern France. Journal of Fish Biology, 18, 271-290.
Crook D.A., Macdonald J.I., McNeil D.G., Gilligan D.M., Asmus M., Maas R. et al. (2013) Recruitment sources and dispersal of an invasive fish in an large river system as revealed by otolith chemistry analysis. Canadian Journal of Fisheries and Aquatic Sciences, 70, 953-963.

D'hondt B. \& Hoffmann M. (2011) A reassessment of the role of simple seed traits in mortality following herbivore ingestion. Plant Biology, 13, 118-124.

Doupé R.G. \& Burrow D.W. (2008) Thirty years later, should we be more concerned for the ongoing invasion of Mozambique Tilapia in Australia? Pacific Conservation Biology, 14, 235-238.

Durka W. \& Michalski S.G. (2012) Daphne: a dated phylogeny of a large European flora for phylogenetically informed ecological analyses: ecological archives E093214. Ecology, 93, 2297.

Figuerola J. \& Green A.J. (2002) Dispersal of aquatic organisms by waterbirds: a review of past research and priorities for future studies. Freshwater Biology, 47, 483-494.

Figuerola J. \& Green A.J. (2004) Effects of seed ingestion and herbivory by waterfowl on seedling establishment: a field experiment with wigeongrass Ruppia maritima in Doñana, south-west Spain. Plant Ecology, 173, 33-38.

Flörchinger M., Braun J., Böhning-Gaese K. \& Schaefer H.M. (2010) Fruit size, crop mass, and plant height explain choice of primates and birds. Oecologia, 164, 151161.

Galetti M., Donatti C.I., Pizo M.A. \& Giacomini H.C. (2008) Big fish are the best: seed dispersal of Bactris glaucescens by the Pacu Fish (Piaractus mesopotamicus) in the Pantanal, Brazil. Biotropica, 40, 386-389.

García-Berthou E. (2001) Size and depth-dependent variation in habitat and diet of the common carp (Cyprinus carpio). Aquatic Sciences, 63, 466-476.

Gardener C.J., McIvor J.G. \& Jansen A. (1993) Passage of legume and grass seeds through the digestive tract of cattle and their survival in faeces. Journal of Applied Ecology, 30, 63-74.

Green A.J., Jenkins K.M., Bell D., Morris P.J. \& Kingsford R.T. (2008) The potential role of waterbirds in dispersing invertebrates and plants in arid Australia. Freshwater Biology, 53, 380-392.

Hay F., Probert R. \& Dawson M. (2008) Laboratory germination of seeds from 10 British species of Potamogeton. Aquatic Botany, 88, 353-357.

Hintze C., Heydel F., Hoppe C., Cunze S., König A. \& Tackenberg O. (2013) $\mathrm{D}^{3}$ : the dispersal and diaspore database - baseline data and statistics on seed dispersal. Perspectives in Plant Ecology, Evolution and Systematics, 15, 180192.

Horn M.H., Correa S.B., Parolin P., Pollux B.J.A., Anderson J.T., Lucas C. et al. (2011) Seed dispersal by fishes in tropical and temperate fresh waters: the growing evidence. Acta Oecologica, 37, 561-577. 
Hutchison M., Sarac Z. \& Norris A. (2011) The Potential for Mozambique Tilapia Oreochromis mossambicus to Invade the Murray-Darling Basin and the Likely Impacts: A Review of Existing Information. Australian Government, Department of Employment, Economic Development and Innovation. Murray Darling Basin Authority. Available at: http:/ / www.mdba.gov.au/sites/default/files/pubs/Tila pia-report.pdf.

Janzen D.H. (1984) Dispersal of small seeds by big herbivores. American Naturalist, 123, 338-353.

Jones M.J. \& Stuart I.G. (2009) Lateral movement of common carp (Cyprinus carpio L.) in a large lowland river and floodplain. Ecology of Freshwater Fish, 18, 72-82.

Kleyer M., Bekker R.M., Knevel I.C., Bakker J.P., Thompson K., Sonnenschein M. et al. (2008) The LEDA Traitbase: a database of life-history traits of the Northwest European flora. Journal of Ecology, 96, 1266-1274.

Koehn J.D. (2004) Carp (Cyprinus carpio) as a powerful invader in Australian waterways. Freshwater Biology, 49, 882894.

Krogdahl A., Hemre G.-I. \& Mommsen T.P. (2005) Carbohydrates in fish nutrition: digestion and absorption in postlarval stages. Aquaculture Nutrition, 11, 103-122.

Latorre L., Larrinaga A.R. \& Santamaria L. (2013) Combined impact of multiple exotic herbivores on different life stages of an endangered plant endemism, Medicago citrina. Journal of Ecology, 101, 107-117.

Lobova T.A., Mori S.A., Blanchard F., Peckham H. \& Charles-Dominique P. (2003) Cecropia as a food resource for bats in French Guiana and the significance of fruit structure in seed dispersal and longevity. American Journal of Botany, 90, 388-403.

Mol J.H. \& Van der Lugt F.L. (1995) Distribution and feeding ecology of the African tilapia Oreochromis mossambicus (Teleostei, Perciformes, Cichlidae) in Suriname (South America) with comments on the Tilapia-Kwikwi (Hoplosternum littorale) (Teleostei, Siluriformes, Callichthyidae) interaction. Acta Amazonica, 25, 101-116.

Muenscher W.C. (1936) Storage and Germination of Seeds of Aquatic Plants. pp. 1-17. Cornell University Agricultural Experiment Station, Bulletin, 652, Ithaca, NY.

Nathan R. (2006) Long-distance dispersal of plants. Science, 313, 786-788.

Nathan R. (2007) Total dispersal kernels and the evaluation of diversity and similarity in complex dispersal systems. In: Seed Dispersal, Theory and its Application in a Changing World (Eds A.J. Dennis, E.W. Schupp, R.J. Green \& D.A. Westcott), pp. 252-276. CABI Publishing, Wallingford, U.K.

Nathan R., Schurr M., Spiegel O., Steinitz O., Trakhtenbrot A. \& Tsoar A. (2008) Mechanisms of long-distance seed dispersal. Trends in Ecology and Evolution, 23, 638-647.

Paradis E., Claude J. \& Strimmer K. (2004) APE: analyses of phylogenetics and evolution in R language. Bioinformatics, 20, 289-290.
Pollux B.J.A. (2011) The experimental study of seed dispersal by fish (ichthyochory). Freshwater Biology, 56, 197212.

Pollux B.J.A., De Jong M.A., Steegh A., Ouborg N.J., Van Groenendael J.M. \& Klaassen M. (2006) The effect of seed morphology on the potential dispersal of aquatic macrophytes by the common carp (Cyprinus carpio). Freshwater Biology, 51, 2063-2071.

Pollux B.J.A., Ouborg N.J., Van Groenendael J.M. \& Klaassen M. (2007) Consequences of intra-specific seed-size variation in Sparganium emersum for dispersal by fish. Functional Ecology, 21, 1084-1091.

Ramos M.E., Robles A.B. \& Castro J. (2006) Efficiency of endozoochorous seed dispersal in six dry-fruited species (Cistaceae): from seed ingestion to early seed establishment. Plant Ecology, 185, 97-106.

R-Development-Core-Team (2013) R: A Language and Environment for Statistical Computing. R Foundation for Statistical Computing, Vienna, Austria. ISBN 3-900051-07-0. Available at: http://www.R-project.org.

Riis T. \& Sand-Jensen K. (2006) Dispersal of plant fragments in small streams. Freshwater Biology, 51, 274-286.

Rodríguez-Pérez J., Riera N. \& Traveset A. (2005) Effect of seed passage through birds and lizards on emergence rate of Mediterranean species: differences between natural and controlled conditions. Functional Ecology, 19, 699706.

Saha S., Roy R.N., Sen S.K. \& Ray A.K. (2006) Characterization of cellulase-producing bacteria from the digestive tract of tilapia, Oreochromis mossambica (Peters) and grass carp, Ctenopharyngodon idella (Valenciennes). Aquaculture Research, 37, 380-388.

Schaefer H.M. \& Schaefer V. (2007) The evolution of visual fruit signals: concepts and constraints. In: Seed Dispersal, Theory and its Application in a Changing World (Eds A.J. Dennis, E.W. Schupp, R.J. Green \& D.A. Westcott), pp. 59-78. CABI Publishing, Wallingford, U.K.

Sibbing F.A. (1988) Specializations and limitations in the utilization of food resources by the carp, Cyprinus carpio: a study of oral food processing. Environmental Biology of Fishes, 22, 161-203.

Sibbing F.A., Osse J.W.M. \& Terlouw A. (1986) Food handling in the carp (Cyprinus carpio): its movement patterns, mechanisms and limitation. Journal of Zoology Series A, 210, 161-203.

Sibbing F.A. \& Witte F. (2005) Adaptations to feeding in herbivorous fish (Cyprinidae and Cichlidae). In: Periphyton: Ecology, Exploitation and Management (Eds M.E. Azim, M.C.J. Verdegem, A.A. van Dam \& M.C.M. Beveridge), pp. 113-140. CABI Publishing, Wallingford, U.K.

Soomers H., Karssenberg D., Soons M.B., Verweij P.A., Verhoeven J.T.A. \& Wassen M.J. (2013) Water and wind dispersal of wetland plants across fragmented landscapes. Ecosystems, 16, 434-451. 
Soons M.B., van der Vlugt C.B., van Lith B., Heil G.W. \& Klaassen M. (2008) Small seed size increases the potential for dispersal of wetland plants by ducks. Journal of Eco$\log y$, 96, 619-627.

Sumoski S.E. \& Orth R.J. (2012) Biotic dispersal in eelgrass Zostera marina. Marine Ecology Progress Series, 471, 1-10.

Tewksbury J.J. \& Nabhan G.P. (2001) Directed deterrence by capsaicin in chillies. Nature, 412, 403-404.

Thompson K., Band S.R. \& Hodgson J.G. (1993) Seed size and shape predict persistence in soil. Functional Ecology, 7, 236-241.

Thompson K., Dunmail L.C., Hodkinson J. \& Rees M. (2002) Seed dispersal: the search for trade-offs. In: Dispersal Ecology (Eds J.M. Bullock, R.E. Kenward \& R.S. Hails), pp. 152-172. Blackwell Publishing, Oxford, U.K.

Thompson K. \& Grime J.P. (1983) A comparative study of germination responses to diurnally-fluctuating temperatures. Journal of Applied Ecology, 20, 141-156.

Traveset A., Robertson A.W. \& Rodríguez-Pérez J. (2007) A review on the role of endozoochory in seed germination. In: Seed Dispersal, Theory and its Application in a Changing World (Eds A.J. Dennis, E.W. Schupp, R.J. Green \& D.A. Westcott), pp. 78-104. CABI Publishing, Wallingford, U.K.

Trewevas E. (1983) Tilapiine Fishes of the Genera Sarotherodon, Oreochromis and Danakilia. British Museum of Natural History, publication number 878. Comstock Publishing Associates, Ithaca, NY.

Van der Meij M.A.A. \& Bout R.G. (2000) Seed selection in the Java Sparrow (Padda oryzifora): preference and mechanical constraint. Canadian Journal of Zoology, 78, 1668-1673.

Van Leeuwen C.H.A., Van der Velde G., Van Groenendael J.M. \& Klaassen M. (2012) Gut travellers: internal dispersal of aquatic organisms by waterfowl. Journal of Biogeography, 39, 2031-2040.
Verberk W.C.E.P., van Noordwijk C.G.E. \& Hildrew A.G. (2013) Delivering on a promise: integrating species traits to transform descriptive community ecology into a predictive science. Freshwater Science, 32, 531-547.

de Vlaming V. \& Proctor V.W. (1968) Dispersal of aquatic organisms: viability of seeds recovered from the droppings of captive killdeer and mallard ducks. American Journal of Botany, 55, 20-26.

Yang X.J., Baskin J.M., Baskin C.C. \& Huang Z.Y. (2012) More than just a coating: ecological importance, taxonomic occurrence and phylogenetic relationships of seed coat mucilage. Perspectives in Plant Ecology Evolution and Systematics, 14, 434-442.

\section{Supporting Information}

Additional Supporting Information may be found in the online version of this article:

Appendix S1. Seed hardness or cracking resistance $( \pm S D)$ of the plant species used.

Appendix S2. Phylogenetic analyses including the phylogenetic tree of the plant species used.

Appendix S3. Proportion of viability and germination of seeds of the control seeds.

Appendix S4. Viability of the number of retrieved seeds compared to the viability of the control seeds.

Appendix S5. Proportion of retrieved seeds that germinated relative to the germination of the control seeds.

Appendix S6. Germination speed of retrieved seeds compared to that of the control seeds.

(Manuscript accepted 26 January 2015) 